\title{
Combining Design Thinking and the Socio-Technical-Ecological Systems Perspective to Understand Greenhouse Growers' Experiences with Energy Management Solutions
}

\author{
Jacqueline Corbett \\ Université Laval \\ jacqueline.corbett@fsa.ulaval.ca
}

\author{
Vijaya Lakshmi \\ Université Laval \\ vijaya.lakshmi.1@ulaval.ca
}

\begin{abstract}
Multiple threats to sustainability are driving the need to grow food in controlled environments, such as greenhouses. However, greenhouses consume large quantities of energy for lighting, heating, and ventilation, which places additional strain on the natural environment. For both business and environmental benefits, greenhouses must pursue sustainable energy management solutions. Combining design thinking with the socio-technical-ecological systems (STES) perspective, we analyze the greenhouse grower's journey from awareness of potential solutions to post-implementation use. Our approach offers a novel way to understand the problem space. We find that sustainable energy management is more than a technical or even sociotechnical challenge; it also involves important ecological considerations. However, ecological and social concerns are less evident in the grower's journey as compared to the physical and information technology dimensions. The research and development of sustainable technology solutions would benefit from giving equal attention to these three systems and the interactions between them.
\end{abstract}

\section{Introduction}

Increasing negative impacts of climate change, limited availability of water resources, and erratic weather patterns are putting pressure on food production systems. With the added effects of the global pandemic, the world is facing the possibility of a prolonged food crisis affecting millions of people [1]. Greenhouses offer a means to counteract uncertainty and unpredictability in the natural environment by providing controlled environments with efficient resource utilization and increased yield compared to open field farming [2, 3]. Worldwide, an estimated 1.2 million acres were used in 2019 for vegetable greenhouses, part of the 13.9 million acres of total global protected agriculture area [4].

Despite the potential for greenhouse and protected agriculture to address food scarcity concerns, these practices face their own sustainability challenges in terms of energy consumption, which can account for up to $50 \%$ of the cost of greenhouse production [5] and high carbon emissions, depending on the source of electricity. For both business and environmental benefits, greenhouse growers must pursue sustainable energy management solutions, which include information systems (IS) for monitoring and managing energy consumption, energy efficiency programs, clean energy initiatives, and renewable energy generation. The adoption and implementation of energy management solutions is a challenging undertaking [3] and greenhouse growers face important hurdles in realizing their energy management goals. The aim of this study is to explore the experience of greenhouse growers with sustainable energy management solutions with a view to aiding the design of more effective solutions.

Addressing today's complex, dynamic, and interconnected problems demands radically different ways of framing those problems and conceiving solutions [6]. We combine two perspectives in a novel approach to understand challenges related to sustainable energy management in greenhouses: design thinking (DT) and the socio-technicalecological systems (STES) perspective. DT is an innovative way to improve software solutions by focusing the design of a product around the concerns, interests, and values of the users [7]. The first stage of design thinking, empathy, involves putting oneself in the position of the user to gain a rich appreciation of their experience or 'journey' with a particular system.

While DT forces a system designer to examine the users' experiences from many perspectives, it does not place any particular emphasis on dimensions of sustainability. This omission raises the risk of unanticipated negative ecological outcomes associated 
with the developed solutions. IS scholars have been called upon to expand their work beyond traditional disciplinary boundaries [8] and to find new ways of framing and solving sustainability problems. The STES perspective provides a path forward by extending beyond the sociotechnical perspective to consider the interactions between people, technology, and the natural environment [9].

Combining DT with the STES perspective, we pursue two related research questions: what is the greenhouse grower's experience in adopting and using energy management solutions and how do social, technical, and ecological considerations come into play during this experience. To answer these questions, we construct a typical greenhouse grower's journey map for sustainable energy management solutions based on interviews with growers, solution vendors, and other industry stakeholders. Then we overlay the social, technical (physical and information technology), and ecological considerations that arise at different points in that journey. By mapping the journey taken by greenhouse growers in this way, we provide a new way of conceptualizing the problem of sustainable energy management in greenhouses and highlight opportunities for novel solution development.

We structure the paper as follows. In section 2, we provide background on DT, STES, and greenhouse energy management. In section 3 , we describe the research methodology. In section 4 , we present the results and follow with a discussion in Section 5. We conclude the paper in Section 6 by highlighting contributions and acknowledging limitations.

\section{Background}

\subsection{Design thinking}

DT is a product development approach "that uses the designer's sensibility and methods to match people's needs with what is technologically feasible and what a viable business strategy can convert into customer value and market opportunity" [10, p. 85]. DT focuses on understanding the user's behavior and thinking through empathy and observation. DT requires close involvement and association of different stakeholders to discover new questions about the problem and reveal underlying assumptions. These investigations can inspire potential solutions that can then be tested and validated before the generation of the end product.

The DT process comprises five stages: empathy, design, ideation, prototype, and test [11]. The empathy stage involves understanding the pain points and needs of users [12]. It also involves understanding the latent desires of users by examining the users' environment, their roles, and their interactions in and with the use environment. This is followed by the define stage, where the information gathered in the first stage is accumulated, analyzed, and synthesized to specify the core problems. The third stage involves brainstorming or "thinking outside the box," to find innovative solutions to the specified problem. The fourth stage is an experimental phase, where a potential solution, or prototype, is crafted for the problems. Finally, the fifth stage involves testing the prototype and gaining feedback and subsequent iterations.

This research is situated in the first stage of DT, empathy. Empathy is an integral component of a usercentered approach to problem-solving as it provides a more profound comprehension of the problem by setting aside personal assumptions and concentrating on the user's aspects involved with the problem [12]. Various methods help to achieve the objectives of the empathy stage. In terms of data collection, surveys, interviews, and focus group discussions are common. These methods initiate a one-to-one connection with the users and provide insights into users' deeper emotional and physical needs. The experiences shared by the users during these activities can be represented in the form of journey maps, empathy maps, and job stories. Journey maps, a key part of human centered design, are visual representations of the processes undertaken by an individual [13]. Such representations act as useful tools in bringing out the user's perspectives and exploring new ideas [14].

Software designers have adopted DT to enhance customer experience [15] and DT is successfully being applied in information technology (IT), healthcare, business, engineering, and law [16]. Journey maps have been used to examine the possibilities of digital transformations in the banking sector [17] and improve the development of an enterprise portal in telecommunications [18]. DT could be a useful approach to solve complex socio-ecological problems [19] because it takes a systemic perspective that explores the embeddedness of the problem in the surrounding systems. However, it does explicitly address dimensions of sustainability and the use of DT to tackle sustainability issues has received little attention [20]. To address these limitations, we suggest that integrating the STES perspective with DT represents a promising path forward.

\subsection{Socio-technical-ecological systems}

While IS researchers have embraced the tight relationship between IS and social systems [21], the community has been slower to recognize the relationships between IS and ecological systems. 
Green IS research has taken strides in this area by investigating how IS can be used to address environmental problems [8]. Still, much of the extant research takes a technological deterministic approach and considers the natural environment as an exogenous factor. In contrast, the STES approach recognizes at least four points of interactions between technologies and human and natural systems [22].

First, when it comes to ecological systems, technology is a double-edged sword that creates mixed feelings and outcomes [22]. This dual reality has been recognized in green IS, with some suggesting that IT is responsible for the negative impacts while Green IS represents a solution [23]. This distinction, however, ignores the continuing negative effects that IS can have on the planet as people appropriate systems in different ways. Artificial intelligence (AI) for sustainability is just one example of the social and ecological ambivalence that technology can create [24].

Second, technology is an increasingly important mediator through which people interact with nature. This means our understanding of the world is largely influenced by the representations furnished by technologies [22]. At the individual level, this role of mediation can be seen in new gamified applications that encourage more sustainable energy use [25].

Third, in mediating the human-environment relationship, technology also transforms human agency and capacity to act [22]. In certain situations, technology may have enabling effects. In the agricultural sector, for example, new technologies, such as tractors [26] and irrigation systems [27], give farmers more control over decisions and actions. On the other hand, new technology interventions can also create new limits and constraints within the social and ecological systems [22, 28].

Fourth, technology changes the scale of interactions between people and the environment in terms of time and space [22]. Through technology, human impact on the planet has increased in scope, intensified, accelerated and been extended in time and space at all levels [22]. In agriculture, technology has opened the possibility of genetically modifying species in order to create crops that are more resilient or climate-appropriate [29], local farm markets have been replaced with large grocers [30] and mobile applications allow people to avoid the physical experience of buying food altogether [31].

From this discussion, we observe that social, technical, and ecological concerns are increasingly intertwined. Adopting the STES perspective means rethinking how and why we frame research problems in a certain way, what questions are asked, what objects are studied, and what methodologies are applied [22]. From the start, researchers must give equal attention to the three dimensions - people, technology, and the natural environment - with the understanding that they operate as an inter-related network of systems with dynamic and emergent qualities [22]. Research also needs to explore how technology shapes the human-nature relationship and the resulting consequences not only on nature, but also on people and technology [22]. Finally, research should also seek to identify strategic interventions and solutions that incorporate the values of reciprocity and well-being for human and planetary systems [22]. We attempt to respond to these requirements as we explore the greenhouse grower's experiences with sustainable energy management solutions.

\subsection{Greenhouse energy management}

Climate change, declining water availability, and erratic weather patterns are evoking the need to grow food under controlled environments. Greenhouse farming is one such strategy. Greenhouse farming produces agricultural products in self-sufficient "controlled environments" with systems supplying heat, water, and nutrients, and often employing artificial lighting (in addition to sunlight) to nourish the plants [2]. The controlled environment of greenhouses allows crop production in harsh climates and extends cultivation seasons for seasonal crops [3]. Controlled environment agriculture (CEA) increases yield, reduces transportation distances, decreases water and land consumption, and reduces the need for pesticides. However, CEA requires careful regulation of temperatures, humidity, light, and water use for maintaining an ideal environment for crop growth. Hence, greenhouses are energy intensive, with energy cost being the biggest cost after labor cost [5]. With increasing energy costs and a push toward cleaner energy, the greenhouse industry requires innovative solutions to lower costs, increase efficiency, and improve productivity [2] and sustainability.

Energy management is a critical aspects of greenhouse farming and involves the proper control and management of temperature, humidity, $\mathrm{CO}_{2}$ levels, and illumination [3]. However, due to the dynamic and non-linear nature of the greenhouse environment, the proper control of these parameters is a complicated process. To help growers with real-time monitoring and decision-making regarding the environmental conditions within the greenhouse, advanced techniques such as wireless sensor networks and control algorithms have been introduced into greenhouse systems [32]. Although these IS approaches have shown promising results, issues related to sensor inaccuracy due to spatial limitations, 
adverse environmental conditions [33], sensor drifts [34], and data security pose a threat to their adoption. Apart from technological limitations, high costs and the upfront investment needed for implementing advanced energy management solutions also hinder their adoption [28]. To develop high impact solutions that overcome these hurdles, system designers require a comprehensive understanding of the grower's experiences and the social, technical, and ecological considerations that come into play.

\section{Methodology}

\subsection{Data collection}

We collected data through semi-structured interviews. We identified potential participants using online directories of greenhouses and invited professional greenhouse growers, vendors, and greenhouse associations within Canada to participate. Nine participants were interviewed between June and October 2020: five greenhouse growers, two greenhouse solution providers, and two representatives from industry associations. The interview protocol was designed to capture key elements of the grower experience with energy management solutions. It contained questions related to the problems growers face at their workplace, their opinions about energy management, their motivations, experiences, and future endeavors for sustainable energy management within greenhouses. From the base protocol, questions were tailored according to participant's specific role. The interviews were conducted in English using web conference tools and ranged from 35 to 70 minutes. All interviews were recorded and transcribed verbatim. We conducted 473 minutes of formal interviews, resulting in 163 pages of single-spaced transcripts. We also received clarifying information from participants via email.

\subsection{Data analysis}

We undertook two main cycles of qualitative data analysis using NVivo to store and organize the data and analytic results. The first cycle involved descriptive coding to attach labels to chunks of data [35]. Three main sets of coding were done: two inspired from DT and one from STES. We developed a coding guide based on the principles of the empathy stage of DT to capture greenhouse and grower characteristics (see Table 1). Each author separately coded two interviews followed by a discussion among the authors to reach a consensus on the coding and coding guide. The remaining interviews were coded by the second author and a research assistant. Disagreements in coding were discussed until mutual agreement was reached. Next, the second author coded the data according to the main phases of activities that comprise the journey of a greenhouse grower: awareness and information gathering, decisionmaking, implementation, and post implementation use. Third, the first author coded the data to identify data chunks related to STES. The technical component was split between physical technologies and information technologies as indicated in Table 1. Following first level coding, we performed sub-coding to identify common themes. The coding for activities and STES dimensions was subsequently reviewed by the other author who did not do the initial coding.

Table 1. First cycle coding structure

\begin{tabular}{|l|l|}
\hline Category & $\mathbf{1}^{\text {st }}$ level codes \\
\hline $\begin{array}{l}\text { Greenhouse } \\
\text { characteristics }\end{array}$ & $\begin{array}{l}\text { Business activities, greenhouse } \\
\text { classification, energy management } \\
\text { solutions and strategies }\end{array}$ \\
\hline $\begin{array}{l}\text { User/actor } \\
\text { characteristics }\end{array}$ & Emotions [36], persona [37] \\
\hline $\begin{array}{l}\text { User/actor } \\
\text { focus }\end{array}$ & $\begin{array}{l}\text { Influence [38], obstacles or pain } \\
\text { points [39], expectations [40], } \\
\text { objectives [41] }\end{array}$ \\
\hline $\begin{array}{l}\text { User/actor } \\
\text { perspective }\end{array}$ & $\begin{array}{l}\text { Experience [41], reflection [42], } \\
\text { opinion[40] }\end{array}$ \\
\hline Activities & $\begin{array}{l}\text { Awareness and information } \\
\text { gathering, decision-making, } \\
\text { implementation, post- } \\
\text { implementation [43] }\end{array}$ \\
\hline $\begin{array}{l}\text { STES } \\
\text { dimensions }\end{array}$ & $\begin{array}{l}\text { Social, physical technology, } \\
\text { information technology, } \\
\text { ecological [22] }\end{array}$ \\
\hline
\end{tabular}

The second cycle of analysis involved creating matrices to display and interpret the data [35]. We used the coded data to construct detailed journey maps. Although our focus is on grower experiences, we developed journey maps for growers, solution providers, and associations. By considering the experiences of the two other actors, we gained insights into interactions and influence, leading to a fuller understanding of the grower's journey. The journey maps were developed by the second author and were refined in discussions between the two authors until there was agreement that they accurately represented the data. Once we were satisfied with our understanding of the grower's journey, we used matrix reports to identify at which point the STES dimensions entered the grower's experience. We rated the relevance of these dimensions as high, moderate, and low (represented as full or semi circles in Figure 1). 


\section{Results}

\subsection{Greenhouse energy management solutions}

Consistent with the literature, our findings confirm that sustainable energy management is an important preoccupation for greenhouse growers. However, we observe that its importance is driven more by economic considerations than ecological ones, as illustrated by one participant's comment:

In terms of energy management, it's very, very key. Greenhouses are in the enclosed production system, so they have a chance to manage the interior environment for the crop very closely. Energy represents [a] really huge amount of the input costs for greenhouse growers.

Practicing CEA allows growers more opportunities to control otherwise uncontrollable factors, such as temperature, air quality, soil quality, and irrigation. Paradoxically, this also puts more pressure on growers to monitor and manage these different parameters to achieve optimal production conditions and outcomes.

Our findings also show that growers confront diverse social, technical, and ecological concerns before, during, and after implementing energy management solutions, as summarized in Table 2.

Table 2. STES concerns identified in study

\begin{tabular}{|l|l|}
\hline $\mathbf{1}^{\text {st }}$ level code & STES concerns \\
\hline Ecological & $\begin{array}{l}\text { Carbon footprint, temperature, } \\
\text { water, climate and outside } \\
\text { weather, greenhouse air quality, } \\
\text { plant health and energy, light, } \\
\text { chemical use }\end{array}$ \\
\hline $\begin{array}{l}\text { Information } \\
\text { technology }\end{array}$ & $\begin{array}{l}\text { Artificial intelligence, automation, } \\
\text { data and analytics, environmental } \\
\text { controls, internet connectivity, } \\
\text { sensors and internet of things, } \\
\text { systems integration }\end{array}$ \\
\hline Physical \\
technology & $\begin{array}{l}\text { Cogeneration, energy efficiency } \\
\text { and conservation, energy storage, } \\
\text { environmental controls, renewable } \\
\text { energy, robots, and automation }\end{array}$ \\
\hline Social & $\begin{array}{l}\text { Lack of knowledge (energy } \\
\text { management, IS, plant energy), } \\
\text { inter-organizational collaboration, } \\
\text { internal collaboration, market, and } \\
\text { regulatory structures }\end{array}$ \\
\hline
\end{tabular}

Within greenhouses, energy management solutions include both physical technologies and combined cyberphysical systems. Environmental control systems for managing temperature, humidity, irrigation, soil and light are common. While the previous generation of technologies was mostly mechanical, the next generation environmental control systems are becoming 'smarter' by leveraging the internet of things, data analytics, and AI, as described by one grower:

It [the system] does light requirements, manages our irrigation systems and manages our shake curtain systems. It manages our airflow. It manages our heating. We call it an environmental control system, it basically controls all the greenhouse mechanisms that allow you to grow a plant. Before it just did the basics. It did open up the vents when you needed them opened. [It] increased the temperature when you need it increased, but it didn't record anything. It wasn't smart. It just did what you told it to do. And now, the new system is [smarter], there's more machine learning. They have an AI component and a lot more data management and data analysis.

The four most discussed energy management solutions after environmental control systems were renewable energy generation (e.g., solar, biomass), cogeneration systems, energy efficiency and conservation initiatives (e.g., efficient lighting), and energy storage through thermal water storage and batteries. The adoption of these technologies depends on the specific requirements of the greenhouse.

\subsection{Grower journey map}

Figure 1 shows the journey map for a typical grower and Table 3 summarizes the objectives, influences, and obstacles at each stage.

The journey toward sustainable energy management solutions starts with gaining awareness and gathering information about energy management solutions and strategies. Growers hear about different solutions in the press and trade media, through their professional networks, and by attending conferences and workshops. During this stage, growers gain confidence in buying a solution, as one participant explained:

If I could read about them [energy management solutions] and make my own evaluation whether it works in [my region], then I would always be interested in looking at it.

Solution providers and consultants are important influences during this stage as they offer information about available solutions and help growers explore the options. Greenhouse consultants, in particular, are viewed as reliable sources when the growers need information about solutions that are appropriate for 
their specific greenhouse conditions and crop requirements.

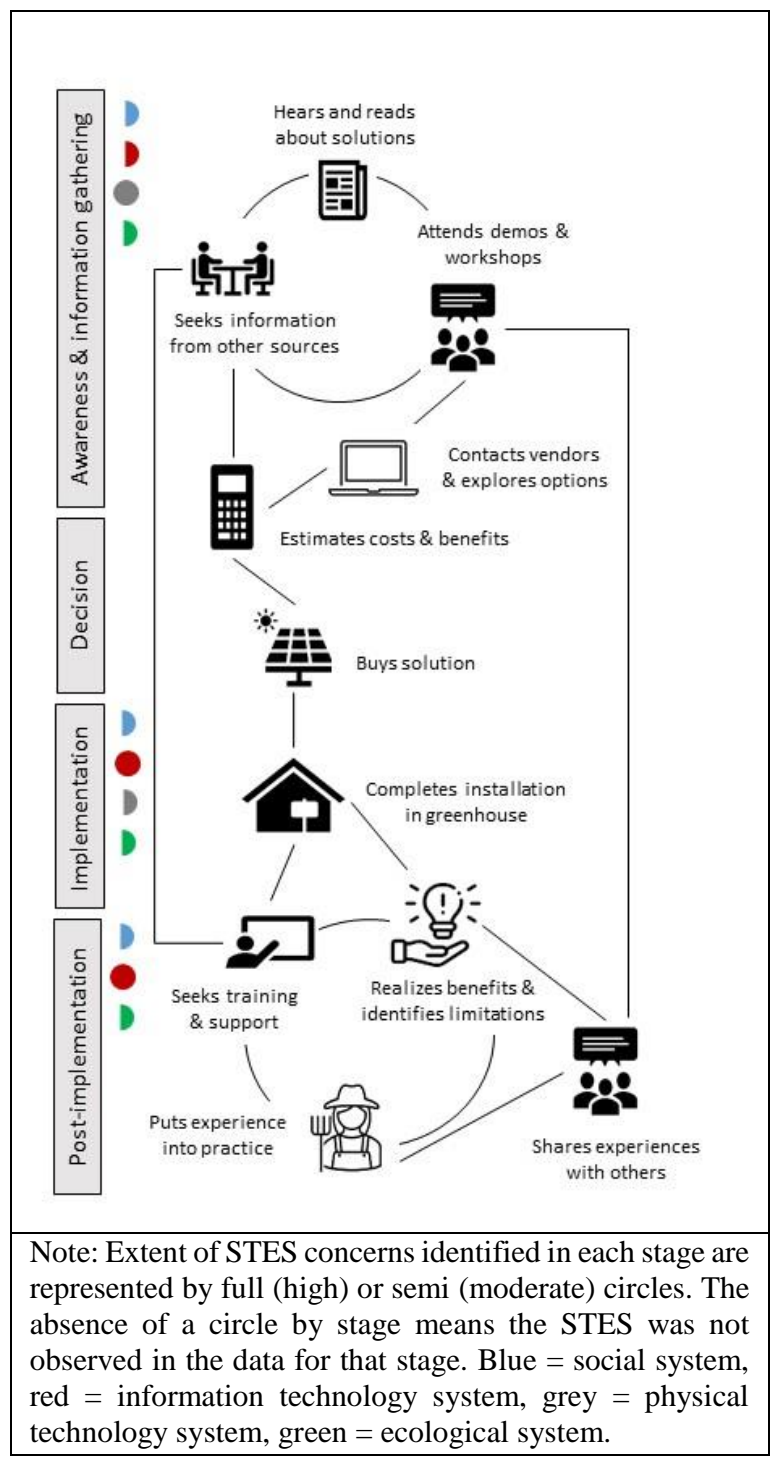

Figure 1. Grower Journey Map

As shown by the colored circles in Figure 1, social, technical, and ecological considerations did not appear equally during the four stages of the grower journey. During the awareness and information gathering stage, questions regarding the physical technologies take center stage as growers gain exposure to and learn about different energy management solutions, in particular energy efficiency and environmental controls. One solution provider spoke of providing growers with a more holistic view of energy management:

When you talk about energy management, some people think its conservation. Then some people talk about being supply management or procurement, but they never dovetail them together. When we do energy management with customers, it's the combination of both, not in isolation with each other.

To a lesser extent, growers also explore different IS that accompany environmental control systems and the potential for new data streams. Ecological concerns at this stage relate to traditional issues, such as control over $\mathrm{CO}_{2}$ levels, temperature, and irrigation controls. Social concerns relate to the need for internal collaboration and collaboration with third parties including solution providers, consultants, associations, and utilities.

In the next stage, the grower makes a decision on purchasing a specific solution. We observed very little discussion of STES considerations in this stage as the decision is driven primarily by economics. Solution providers and consultants help the growers evaluate the solutions on different criteria of solution fit, cost, benefits, incentives, and long-term goals. One solution provider explained their role this way:

From our side, on energy management we have to sell that solution is that...this heat recovery unit could save you and you do the calculations, you know $20 \%$.

The competitive business environment and thin margins for greenhouses mean that a solid financial return is required for a solution to be adopted.

The third stage is implementation of the solution. Here, the involvement of solution providers is key for installation and technological guidance. In many respects this phase is similar to other equipment and IS projects, however, the grower may also engage greenhouse consultants to provide guidance on plant science and systems, as explained below:

He [crop specialist] would be giving me advice, on whether that's a good idea or not. Sometimes he says 'no that's not gonna work. Or yes, if you do it this way.' It's always in cooperation with him'.

During this stage, concerns regarding all four STES are evident. Ecological concerns cover a wide variety of topics from the environmental conditions within the greenhouse (temperature, air quality, irrigation systems, lighting) as well as plant health and $\mathrm{CO}_{2}$ emissions. While $\mathrm{CO}_{2}$ is recognized as an important factor for plant growth, most of the energy efficiency solutions, such as computer climate control systems and solar, concentrate on controlling heat and $\mathrm{CO}_{2}$ rather than generation. Such an approach requires careful consideration because the interactions between ecological and technical systems are crucial for the efficacy of a solution: 
The main thing to remember is that need for plants to have the heat and the $\mathrm{CO}_{2}$ at the same time. So solar energy by itself doesn't provide that $\mathrm{CO}_{2}$ and there's still that need and so purchasing $\mathrm{CO}_{2}$ comes at another cost.

Despite the importance of ecological concerns to the successful implementation of energy management solutions, they seem to take a backseat to the technical systems. Few of the energy management solutions implemented today are pure physical technologies. Rather, they are cyberphysical systems that include both physical and information technology. This technological advancement creates additional challenges for systems integration, as a participant highlighted a key pain point:

Having those systems communicate with legacy systems. In order for these new systems to work properly it's almost like we had to upgrade and find better systems for other aspects of our company because our other stuff is just too old, obsolete almost, in terms of how they can interact with the new energy conservation systems. I would say that is a pretty big pain point.

Table 2 Grower focus by journey stage

\begin{tabular}{|c|c|c|c|c|}
\hline $\begin{array}{l}\text { Grower } \\
\text { Focus }\end{array}$ & $\begin{array}{l}\text { Awareness and } \\
\text { information gathering }\end{array}$ & Decision & Implementation & Post-implementation \\
\hline Objectives & $\begin{array}{l}\text { Gain knowledge about } \\
\text { energy management and } \\
\text { solutions }\end{array}$ & Select a solution & $\begin{array}{l}\text { Achieve successful } \\
\text { implementation }\end{array}$ & $\begin{array}{l}\text { Realize benefits of } \\
\text { system }\end{array}$ \\
\hline Influence & $\begin{array}{l}\text { Vendors and consultants } \\
\text { conduct workshops and } \\
\text { conferences, discussions } \\
\text { with other growers }\end{array}$ & $\begin{array}{l}\text { Vendors and } \\
\text { consultants assist } \\
\text { with evaluation of } \\
\text { specific solution }\end{array}$ & $\begin{array}{l}\text { Vendors provide } \\
\text { installations and } \\
\text { manuals }\end{array}$ & $\begin{array}{l}\text { Discussions with other } \\
\text { growers }\end{array}$ \\
\hline Obstacles & $\begin{array}{l}\text { Lack of awareness and } \\
\text { knowledge of energy } \\
\text { management }\end{array}$ & $\begin{array}{l}\text { Lack of relevant } \\
\text { information }\end{array}$ & $\begin{array}{l}\text { Upfront cost, } \\
\text { retrofitting old } \\
\text { infrastructure, lack of } \\
\text { competent staff }\end{array}$ & $\begin{array}{l}\text { Technical } \\
\text { noncompliance, lack of } \\
\text { competency, harsh } \\
\text { climate, lack of } \\
\text { knowledge about plant } \\
\text { systems }\end{array}$ \\
\hline
\end{tabular}

In addition, new solutions often come with data collection and software tools for monitoring and realtime management such that growers experience new pressures within the social system, specifically around the lack of knowledge within greenhouse organizations:

Our Cogen unit comes with the system and backend and a lot of software that is connected to a lot of our other systems but it's highly complicated and we don't have anyone internally who has the necessary experience or knowledge to run that systems.

Due to this challenge, growers have a continued need to collaborate both internally and externally with solution providers and other experts.

The final stage is post-implementation, during which growers use the new energy management solution. They may seek additional training and technical support and put their experiences into practice. The grower begins to realize the benefits of the implemented solution, but also discovers its limitations. During this stage, attention to the physical technologies subsides as solutions such as lighting, heating and ventilation and solar power generation tend to be stable with routine maintenance. However, IT concerns continue to be prominent. The following quote illustrates how external collaboration can help greenhouses to maintain their systems and take advantage of the data to inform different parts of the business:

Every aspect of the system gets some kind of maintenance whether it be a physical cleaning or a backup [of] data. Other than that, there's just monitoring everything with the system communicating with our outside people... their main job is just to keep the system running smoothly to gather as much data as they can and to disseminate that data to people that would be interested in that information.

In some cases, greenhouses hire additional staff to fill knowledge gaps and manage the systems:

We had to hire someone who really pretty much only deals with our environmental controls and energy conservation. They make sure that the systems are working together, [collecting] as much data as possible, and making small improvements based on the historical data what are we doing well, where can we improve. And 
that's almost their full-time job and they work [in] close conjunction with our growers.

Through these collaborations and with use growers acquire new knowledge of the physical and information systems as well as ecological systems. They are then able to identify limitations and training gaps. Growers' post-implementation experiences trigger feedback loops as they share their stories and questions with others in their professional networks and seek to improve energy management practices.

Overall, our study suggests greenhouses realize notable business and environmental benefits from implementing energy management solutions. However, the introduction of these solutions can have serious negative consequences when ecological systems are not taken into account. One grower recounted the following experience:

I installed the LED lights and they were so different that within a week of turning them on, [I] actually had to turn them off because there was so much light and we hadn't made any other changes as far as water frequency, temperatures, all these kinds of things. Everything else is still the same that the plants are actually dying. We lost quite a few cuttings in the first week, so I decided just to turn them off, and then just to regroup. So that was a bit of a challenge, but that with the help of [consultant and system] capabilities and settings, I was able to manage that quite quickly and they were only off for about a week and now we're in good shape.

\section{Discussion and implications}

In this research, we set out to explore the greenhouse grower's experience in adopting and using energy management solutions and how dimensions of the social, technical, and ecological systems come into play during this experience. Adopting a novel research approach by combining DT and the STES perspective provides a new way of conceiving the problem faced by growers. We learn that sustainable energy management in the greenhouse sector is not simply a technological or even sociotechnical undertaking, but rather it is a complex, non-linear, and dynamic sociotechnical-ecological systems challenge.

In our discussions with growers and other stakeholders, we discovered that the concept of energy within this context is much broader than electricity to power equipment or fuel for vehicles. To grow, plants require energy derived from heat and light, which in turn may be generated from other sources, such as electricity. This creates a symbiotic relationship between the different systems. As one participant explained to us, a "plant is basically [an] energy management tool." For IS researchers, this statement should prompt us to reflect on our underlying assumptions of green IS and technology more broadly.

A second finding worthy of further reflection is the disparity across different STES dimensions during the four stages of the grower journey. As illustrated in Figure 1, considerations of the social, technical, and ecological systems are concealed by financial criteria during the decision phase. We wonder how the design and implementation of these solutions would differ if environmental metrics were used as part of the decision-making process. In the three other stages, social and ecological systems concerns, while present, were secondary to the technical systems. This result is notable on two fronts. First, with regard to social systems, knowledge and collaboration are areas of expertise within the IS community which could be brought to bear on the transition toward sustainable energy. Second, given the research context, we would have expected more discussion of ecological systems. A possible explanation for this difference may be that technical considerations are more novel and thus more salient to growers, whereas prior experience with environmental control systems mean that ecological concerns were taken for granted. As designers and researchers of IS solutions in agricultural contexts, we need to acknowledge our lack of domain expertise in ecological systems, develop meaningful transdisciplinary collaborations, and provide greater environmental education within the IS curriculum [9].

Finally, by considering both the physical and informational nature of energy management solutions, this research provides new insights into emerging cyberphysical solutions, which characterize Industry 4.0. From the grower journey map, we observe that during the early stages of awareness and information gathering, more attention is given to the physical technologies - energy efficient lighting, cogeneration systems, and renewable energies. These physical systems are complex and often come with significant upfront investment. This may help to explain the early focus. While the information potential of these systems is identified during the awareness stage, the potential benefits and challenges become much more tangible during the implementation and postimplementation stages. Greenhouses face common IT issues of systems integration, technical support, and data analytics capabilities. The greater the opportunity, it seems, the greater the challenge. As the movement toward Industry 4.0 gains momentum, the IS community will need to remain attentive to the mutual interactions and influences between the physical and information technology systems. 


\section{Conclusion}

Through this work, we make two main contributions to the literature. The first contribution is methodological. Although DT is beginning to be used in practice, its application in research is still limited [44]. Inspired by other research [13], we use the empathy phase of DT and journey maps as an analytical approach to structuring and making sense of qualitative data. In addition, we overlay the STES perspective [22] to enrich this analysis. This research can thus serve as an example for other researchers.

Our second contribution is to the green IS literature. At the broadest level, green IS research asks how IS can contribute to environmental sustainability. In this research, we tackle that question from the intersection of sustainable agriculture and sustainable energy management. Both food production and clean energy are important priorities within the United Nations' Sustainable Development Goals. However, these two domains are not independent of each other. Food production systems and energy production systems are each in themselves highly complex and become even more so when intertwined. The IS community has been called to build concrete solutions for sustainability $[8,9]$. The ability to build effective innovative solutions begins with a comprehensive understanding of the problem, and understanding that is not constrained by traditional approaches to problem definition and solution development [6]. Thus, our research, which provides a novel way of conceiving the problem space, offers a step forward for novel solution development.

Prior to concluding, we must acknowledge some limitations of this research. Our findings are based on a relatively small sample size with participants located solely in Canada. Thus, although we believe there is some generalizability, we cannot not claim that the results apply to all the different types of CEA or to greenhouses in other regions that may have different climatic, social, and technological conditions. In addition, our findings regarding the social and ecological systems may have been affected by the design of our interview protocol. During our questioning, we did not specifically probe for concerns in these areas. We did, however, ask open-ended questions about opportunities and challenges. True to the idea of empathy, we tried to allow participants to speak freely about their experiences and to reflect on those which were most salient to them. Additional research and case studies in other settings would help refine and validate the results of the study and we invite other researchers to build on our work to explore these questions and to integrate the STES perspective to enhance their own work.

\section{References}

[1] Harvey, F., "World Faces Worst Food Crisis for at Least 50 Years, UN Warns", https://www.theguardian.com/society/2020/jun/09/worldfaces-worst-food-crisis-50-years-un-coronavirus, 2020. [2] Vox, G., Teitel, M., Pardossi, A., Minuto, A., Tinivella, F., and Schettini, E., "Sustainable Greenhouse Systems": Sustainable Agriculture: Technology, Planning and Management, Nova Science Publishers, Inc., New York, 2010.

[3] Iddio, E., Wang, L., Thomas, Y., Mcmorrow, G., and Denzer, A., "Energy Efficient Operation and Modeling for Greenhouses: A Literature Review", Renewable and Sustainable Energy Reviews, 117, 2020, pp. 1-15.

[4] Produce Grower, "Cuesta Roble Releases 2019 Global Greenhouse Statistics", https://www.producegrower.com/article/cuesta-roble-2019global-greenhouse-statistics/, 2019.

[5] Shen, Y., Wei, R., and Xu, L., "Energy Consumption Prediction of a Greenhouse and Optimization of Daily Average Temperature", Energies, 11(65), 2018, pp. 1-17.

[6] Dorst, K., Frame Innovation: Create New Thinking by Design, Massachusetts Institute of Technology, MA, U.S.A., 2015.

[7] Denning, P.J., "The Profession of IT: Design Thinking", Communications of the ACM, 56(12), 2013, pp. 29-31.

[8] Gholami, R., Watson, R.T., Hasan, H., Alemayehu, M., and Bjorn-Andersen, N., "Information Systems Solutions for Environmental Sustainability: How Can We Do More?", Journal of the Association for Information Systems, 17(8), 2016, pp. 521-636.

[9] Watson, R.T., Elliot, S., Corbett, J., Farkas, D., Feizabadi, A., Gupta, A., Iyer, L., Sen, S., Sharda, R., Shin, N., Thapa, D., and Webster, J., "How the Ais Can Improve Its Contributions to the Un's Sustainability Development Goals: Towards a Framework for Scaling Collaborations and Evaluating Impact", Communication of the Association for Information Systems, 48(Paper 41), 2021, pp. 476-502.

[10] Brown, T., "Design Thinking", Harvard Business Review, 86(6), 2008, pp. 84-95.

[11] Jensen, M.B., Lozano, F., and Steinert, M., "The Origins of Design Thinking and the Relevance in Software Innovations", 17th International Conference PROFES 2016, 2016, pp. 675-678.

[12] Beaird, G., Geist, M., and Lewis, E.J., "Design Thinking: Opportunities for Application in Nursing Education", Nurse Education Today, 64, 2018, pp. 115-118. [13] Sinitskaya, E., Gomez, K.J., Bao, Q., Yang, M.C., and Mcdonald, E.F., "Designing Linked Journey Maps to Understand the Complexity of the Residential Solar Energy Market", Renewable Energy, 145, 2020, pp. 1910-1922.

[14] Nedeltcheva, G.N., and Shoikova, E., "Coupling Design Thinking, User Experience Design and Agile: Towards Cooperation Framework", in (Editor, 'ed.'^'eds.'): Book Coupling Design Thinking, User Experience Design and Agile: Towards Cooperation Framework, 2017, pp. 225229.

[15] Gruber, M., Deleon, N., George, G., and Thompson, P., "Managing by Design", Academy of Management Journal, 58(1), 2015, pp. 1-7. 
[16] Frisk, J.E., Lindgren, R., and Mathiassen, L., "Design Matters for Decision Makers: Discovering IT Investement Alternatives", European Journal of Information Systems, 23(4), 2014, pp. 442-461.

[17] Feher, P., and Varga, K., "Digital Transformation in the Hungarian Banking Industry-Experiences with Design Thinking", Society \& Economy, 41(3), 2019, pp. 293-310.

[18] Vasilieva, E.V., "Developing the Creative Abilities and Competencies of Future Digital Professionals", Automatic Documentation and Mathematical Linguistics, 52(5), 2018, pp. 248-256.

[19] Buhl, A., Schmidt-Keilich, M., Muster, V., Blazejewski, S., Schrader, U., Harrach, C., and Susbauer, E., "Design Thinking for Sustainability: Why and How Design Thinking Can Foster Sustainability-Oriented Inovation Development", Journal of Cleaner Production, 231, 2019, pp. 1248-1257.

[20] Maher, R., Maher, M., Mann, S., and Mcalpine, C.A., "Integrating Design Thinking with Sustainability Science: A Research through Design Approach", Sustainability Science, 13(6), 2018, pp. 1565-1587.

[21] Sarker, S., Chatterjee, S., Xiao, X., and Elbanna, A., "The Sociotechnical Axis of Cohesion for the IS Discipline: Its Historical Legacy and Its Continued Relevance", MIS Quarterly, 43(3), 2019, pp. 695-720.

[22] Ahlborg, H., Ruiz-Mercado, I., Molander, S., and Masera, O., "Bringing Technology into Social-Ecological Systems Research-Motivations for a Socio-TechnicalEcological Systems Approach", Sustainability, 11, 2019, pp. $1-23$.

[23] Dedrick, J., "Green IS: Concepts and Issues for Information Systems Research", Communication of the Association for Information Systems, 27(Article 11), 2010, pp. 173-184.

[24] Nishant, R., Kennedy, M., and Corbett, J., "Artificial Intelligence for Sustainability: Challenges, Opportunities, and a Research Agenda", International Journal of Information Management, 53, 2020, pp. 1-13.

[25] Oppong-Tawiah, D., Webster, J., Staples, S., Camerion, A.-F., Ortiz De Guinea, A., and Tam, Y.H., "Encouraging Sustainable Energy Use in the Office with a Gamified Mobile Application", Journal of Business Research, 106, 2020, pp. 388-405.

[26] Lagnelov, O., Dhillon, S., Larsson, G., Nilsson, D., Larsolle, A., and Hansson, P.A., "Cost Analysis of Autonomous Battery Electric Field Tractors in Agriculture", Biosystems Engineering, 204, 2021, pp. 358-376.

[27] Garcia, L., Parra, L., Jimenez, J.M., Lloret, J., and Lorenz, P., "IoT-Based Smart Irrigation Systems: An Overview on the Recent Trends on Sensors and IoT Systems for Irrigation in Precision Agriculture", Sensors, 20(4), 2020, pp. 1-48.

[28] Abbasi, A.Z., Islam, N., and Shaikh, Z.A., "A Review of Wireless Sensors and Networks' Applications in Agriculture", Computer Standards \& Interfaces, 36(2), 2014, pp. 263-270.

[29] Zaidi, S.S.E.A., Mahas, A., Vanderschuren, H., and Mahfouz, M.M., "Engineering Crops of the Future: Crispr Approaches to Develop Climate-Resilient and DiseaseResistant Plants", Genome Biology, 21(1), 2020, pp. 1-19.
[30] Qaim, M., "Globalisation of Agrifood Systems and Sustainable Nutrition", Proceedings of the Nutrition Society, 76(1), 2017, pp. 12-21.

[31] Emeana, E.M., Trenchard, L., and Dehnen-Schmutz, K., "The Revolution of Mobile Phone-Enabled Services for Agricultural Development (M-Agri Services) in Africa: The Challenges for Sustainability", Sustainability, 12(2), 2020, pp. 1-27.

[32] Lopez-Cruz, I.L., Fitz-Rodriguez, E., TorresMonsivais, J.C., Trejo-Zuniga, E.C., Ruiz-Garcia, A., and Ramirez-Arias, A., "Control Strategies of Greenhouse Climate for Vegetables Production", in (Guevara-Gonzalez, R., and Torres-Pacheco, I., 'eds.'): Biosystems Engineering: Biofactories for Food Production in the Century Xxi, Springer International Publishing, 2014, pp. 401-421.

[33] Ferentinos, K.P., Katsoulas, N., Tzounis, A., Bartzanas, T., and Kittas, C., "Wireless Sensor Networks for Greenhouse Climate and Plant Condition Assessment", Biosystems Engineering, 153, 2017, pp. 70-81.

[34] Bontsema, J., Van Henten, E.J., Gieling, T.H., and Swinkels, G.L.a.M., "The Effect of Sensor Errors on Production and Energy Consumption in Greenhouse Horticulture", Computers and electronics in agriculture, 79(1), 2011, pp. 63-66.

[35] Miles, M.B., Jhuberman, A.M., and Saldana, J., Qualitative Data Analysis: A Methods Sourcebook, Sage Publications, Inc., 3rd edn, Thousand Oaks, CA, 2014.

[36] Weber, H., Rodrigues, A.C., and Mateus, A., "Emotion and Mood in Design Thinking", Design Doctoral Conference '16: Transversality, 2016, pp. 65-72.

[37] Pruitt, J., and Adlin, T., The Persona Lifecycle: Keeping People in Mind Throughout Product Design, Elsevier, 2010. [38] Gibbons, S., "What Is Design Thinking, Really? (What Practitioners Say)", https://www.nngroup.com/articles/design-thinkingpractitioners-say/, 2018.

[39] Wick, J., "Ideation: Solving Pain Points Fast", https://uxdesign.cc/ideation-solving-pain-points-fast6421bddd04fa\#: :text=Pain\%20points \%20are\%20real\%20 or,and\%20solve\%20these\%20problems\%20fast, 2018.

[40] Verfasst, V.A., "Design Thinking Vs Consumer Expectations: How to Ace Both and Come out on Top", https://www.corporate-alchemists.com/design-thinking-vsconsumer-expectations-how-to-ace-both-and-come-out-ontop/, 2017.

[41] Mortensen, D.H., "Stage 1 in Design Thinking Process: Empathise with Your Users", https://www.interactiondesign.org/literature/article/stage-1-in-the-design-thinkingprocess-empathise-with-your-users, 2020.

[42] Zhu, P., "Reflection in Design Thinking", http://futureofcio.blogspot.com/2015/02/reflection-indesign-thinking.html, 2015.

[43] Ortbal, K., Frazzette, N., and Mehta, K., "Stakeholder Journey Mapping: An Educational Tool for Social Entrepreneurs", Procedia Engineering, 159, 2016, pp. 249258.

[44] Liedtka, J., "Perspective: Linking Design Thinking with Innovation through Cognitive Bias Reduction", Journal of Product Innovation Management, 32(6), 2015, pp. 925-938. 